Perhalophenyl Three-Coordinate Gold(I) Complexes as TADF

Emitters : A Photophysical Study from Experimental and Computational Viewpoints

Lopez-de-Luzuriaga, Jose M.

2020-10-05

Lopez-de-Luzuriaga , J M , Monge , M , Elena Olmos , M , Rodriguez-Castillo , M , Soldevilla , I , Sundholm , D \& Valiev , R R 2020 , ' Perhalophenyl Three-Coordinate Gold(I)

Complexes as TADF Emitters : A Photophysical Study from Experimental and

Computational Viewpoints ' , Inorganic Chemistry , vol. 59 , no. 19 , pp. 14236-14244 . https://doi.org/10.1021/acs.in

http://hdl.handle.net/10138/337917

https://doi.org/10.1021/acs.inorgchem.0c02018

unspecified

acceptedVersion

Downloaded from Helda, University of Helsinki institutional repository.

This is an electronic reprint of the original article.

This reprint may differ from the original in pagination and typographic detail.

Please cite the original version. 


\title{
Perhalophenyl Three-coordinate Au(I) Complexes as TADF Emitters: A Photophysical Study from Experimental and Computational Viewpoints.
}

\author{
José M. López-de-Luzuriaga, ${ }^{*+}$ Miguel Monge, ${ }^{+}$M. Elena Olmos, ${ }^{+}$María Rodríguez-Castillo, ${ }^{*+}$ Inés Soldevilla, ${ }^{+}$ \\ Dage Sundholm, ${ }^{*}$ Rashid R. Valiev ${ }^{t, \xi}$ \\ † Departamento de Química. Universidad de la Rioja. Centro de Investigación en Síntesis Química (CISQ). Complejo Científico \\ Tecnológico 26004-Logroño, SPAIN. \\ ${ }^{t}$ Department of Chemistry. Faculty of Science, P.O. Box 55, (A.I. Virtasen aukio 1) FIN-00014 University of Helsinki, FINLAND.

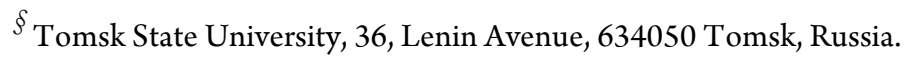

Key words: Gold(I), Thermally activated delayed fluorescence (TADF), Phosphorescence, computational studies, three-coordinate complexes

Supporting Information Placeholder

\begin{abstract}
We report the synthesis of novel perhalophenyl three-coordinated gold(I) complexes using 1,2-bis(diphenylphosphino)benzene (dppBz) as chelating ligand and [AuR(tht)] (R $\left.=\mathrm{C}_{6} \mathrm{~F}_{5}, \mathrm{C}_{6} \mathrm{Cl}_{2} \mathrm{~F}_{3}, \mathrm{C}_{6} \mathrm{Cl}_{5}\right)$ as the perhalophenyl-gold $(\mathrm{I})$ source, leading to $[\mathrm{AuR}(\mathrm{dppBz})]\left(\mathrm{R}=\mathrm{C}_{6} \mathrm{~F}_{5}\right.$ (1), $\mathrm{C}_{6} \mathrm{Cl}_{2} \mathrm{~F}_{3}(\mathbf{2}), \mathrm{C}_{6} \mathrm{Cl}_{5}$ (3)) complexes. The solid-state structures of compounds $\mathbf{2}$ and $\mathbf{3}$ consists of discrete three-coordinated $\mathrm{Au}(\mathrm{I})$ complexes, which show a distorted trigonal planar geometry for the gold center with dissimilar Au-P distances. The distorted structural arrangement is closely related to its photophysical properties. The solid state of the studied complexes displays very intense emissions at room temperature $(\mathrm{RT})$ and at $77 \mathrm{~K}$. Studies of the emissive properties of the complexes at different temperatures suggest that the luminescence is phosphorescent at $77 \mathrm{~K}$ and exhibit thermally activated delayed fluorescence (TADF) at RT. First-principle calculations of the photophysical processes yielded rate constants for intersystem crossing and reverse intersystem crossing that are in excellent agreement with experimental data.
\end{abstract}

\section{INTRODUCTION}

The design and fabrication of organic light-emitting devices (OLEDs) is one of the most important applications of luminescent molecules with high quantum yields. ${ }^{1}$ One of the main goals in the development of novel materials for electroluminescent devices is the design of strategies for the preparation of molecules with the high efficiency. Most of the purely fluorescent organic emitters have a very low light-emission efficiency. Only $25 \%$ of the total number of excitons is converted to photons, because $25 \%$ of the excitons occupy the lowest singlet state, while the rest $(75 \%)$ are in the triplet state. To avoid the loss of $75 \%$ of the excitons in fluorescent OLEDs, the second generation of phosphorescent organometallic emitters for OLEDs were designed such that the singlet excited states undergo fast intersystem crossing to the lowest triplet excited state due to the strong spin-orbit coupling (SOC) caused by the metal, leading to a light-emission efficiency of nearly $100 \%$.However, the main problem of this type of emitters is the long radiative lifetimes, favouring quenching processes or bleaching reactions that reduce their applicability. ${ }^{2}$
A sensible strategy is to harvest the generated triplet excitons and converting them into emissive singlet excitons, which improves the emission efficiency and solves the problems with the pure phosphorescent emitters. The third generation of light-emitting molecules are called Thermally Activated Delayed Fluorescence (TADF) emitters, which have extremely high efficiencies, since they are able to generate light from both singlet and triplet excitons, even at room temperature. The third generation of emitters must fulfil a number of criteria. They must have a small energy difference between the lowest excited singlet state and the lowest triplet state $\left[\Delta \mathrm{E}\left(\mathrm{S}_{1}-\mathrm{T}_{1}\right)\right]$, allowing intersystem crossing (ISC) downwards from $\mathrm{S}_{1}$ to $\mathrm{T}_{1}$ to harvest triplet excitons. They must also have a temperature-dependent reverse ISC (RISC) from $\mathrm{T}_{1}$ to $\mathrm{S}_{1}$ rendering capturing of singlet excitons feasible. An additional requirement of TADF emitters is that they have a rigid molecular structure that avoids significant distortions of the molecular structure of the excited state, preventing non-radiative deactivation pathways.

A common strategy to design TADF emitters consists of synthesizing rigid coordination or organometallic complexes bearing late transition metals and high-steric demand ligands. The first metal-containing compound described as a TADF material was reported by Blasse and McMillin. ${ }^{4}$ It consisted of a tetracoordinated copper(I) complex. It was more recently discovered that copper, ${ }^{5,6}$ not the only metal that is able to form complexes displaying TADF, which has also been observed in complexes containing other metal centres such as $\mathrm{Ag}, \mathrm{Pd}$, Sn or $\mathrm{Zn}$.

Since the discovery of a luminescent gold(I) complex by Dori et al. in $1970,{ }^{8}$ studies of optical properties of gold complexes has made great progress. One has gathered a lot of new knowledge about the connection between structure, composition and properties, leading to a precise control of the optical properties that complexes are expected to have based on their molecular and even supramolecular structure. ${ }^{9}$ The acquired knowledge from a large number of profound experimental and computational studies has made it possible to tune the emission energies to meet the necessary conditions for the purposes or requirements of the molecules. ${ }^{10-12}$ 
It is well-known that the strong spin-orbit coupling (SOC) originating from the gold atom, makes the excited triplet states accessible. However, in spite of the huge number of known luminescent gold(I) complexes, there are very few gold(I) containing TADF emitters, since large SOCs of gold(I) complexes were expected to exclusively lead to phosphorescent processes. The first gold(I) TADF emitter was reported in 2013 by Osawa. ${ }^{13-}$

15 Most of the gold(I) complexes displaying TADF contain phosphine $^{13,16}$ or carbene ligands, ${ }^{17}$ and have a small $\Delta \mathrm{E}\left(\mathrm{S}_{1}-\mathrm{T}_{1}\right)$, which favours the RISC that leads to TADF at room temperature.

Gold(I) complexes exhibit interesting properties that can make them appropriate as TADF emitters: (i) They are expected to have very strong SOCs due to its heavy-metal nature. (ii) There is a possibility of synthesizing complexes with high structural rigidity, for instance three-coordinated gold(I) complexes, disfavouring non-radiative deactivation pathways. (iii) They are very stable and unreactive complexes towards oxidation, which make them appropriate for practical applications.

We present here the synthesis of a new class of TADF emitters consisting of perhalophenyl three-coordinate 1,2bis(diphenylphosphino)benzene (dppBz) gold(I) complexes. The diphosphine was chosen as the rigid ligand that can prevent significant distortions of the molecular structure of the excited states and fast non-radiative deactivation. ${ }^{18}$ Perhalophenyl groups are chosen as the electron source that favours charge transfer processes needed for TADF. The presence of fluorinated ligands facilitates thin-film fabrication ${ }^{19}$ and can improve thermal and oxidative stability and also reduce concentration quenching. ${ }^{20,21}$ These properties are highly desirable in the design of emission devices for practical applications. First-principle computational studies provide, for the first time, the complete assignment of the TADF behaviour for the $\mathrm{Au}(\mathrm{I})$ complexes, including an accurate estimate of the $k_{R I S C}\left(\mathrm{~T}_{1} \rightarrow \mathrm{S}_{1}\right), k_{I S C}\left(\mathrm{~S}_{1} \rightarrow \mathrm{T}_{1}\right)$ and $k_{I S C}\left(\mathrm{~T}_{1} \rightarrow \mathrm{S}_{0}\right)$ rate constants, which are in an excellent agreement with experimental data.

\section{SYNTHESIS AND CHARACTERIZATION.}

In a typical reaction, to a solution of [AuR(tht)] $\left(\mathrm{R}=\mathrm{C}_{6} \mathrm{~F}_{5}(\mathbf{1})\right.$, $\mathrm{C}_{6} \mathrm{Cl}_{2} \mathrm{~F}_{3} \quad$ (2), $\quad \mathrm{C}_{6} \mathrm{Cl}_{5} \quad$ (3); tht $=$ tetrahydrothiophene) in dichloromethane, 1,2-Bis(diphenylphosphino)benzene (dppBz) was added in a 1:1 molar ratio (see Scheme 1). After 30 minutes of stirring, most of the solvent was evaporated under vacuum and the addition of $n$-hexane led to the precipitation of complexes [AuR(dppBz)] $\left(\mathrm{R}=\mathrm{C}_{6} \mathrm{~F}_{5}\right.$ (1), $\mathrm{C}_{6} \mathrm{Cl}_{2} \mathrm{~F}_{3}(\mathbf{2}), \mathrm{C}_{6} \mathrm{Cl}_{5}$ (3)) as yellow solids. The spectroscopic and analytical data agree with the proposed stoichiometries. The IR spectra for the three complexes show, among others, the absorption bands due to the presence of the [Au-R] fragments $\left(\mathrm{R}=\mathrm{C}_{6} \mathrm{~F}_{5}\right.$ (1), $\mathrm{C}_{6} \mathrm{Cl}_{2} \mathrm{~F}_{3}$ (2), $\mathrm{C}_{6} \mathrm{Cl}_{5}$ (3)) located at $v=798,952,1635 \mathrm{~cm}^{-1}(\mathbf{1}), 771,1564,1579,1592 \mathrm{~cm}^{-1}$ (2) and $620,836 \mathrm{~cm}^{-1}(3)$ and the corresponding bands associated to the dppBz ligand in the $v=543-490 \mathrm{~cm}^{-1}$ range (see SI).

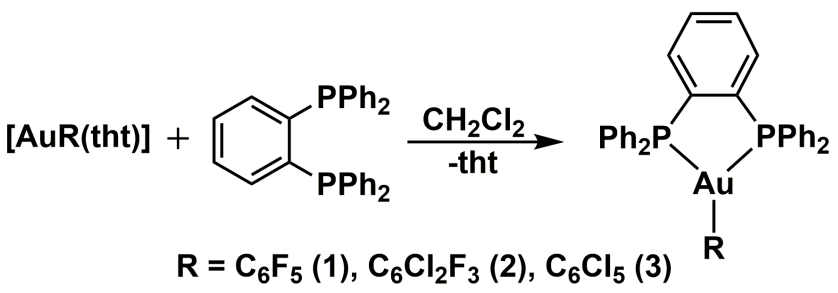

Scheme 1. Synthesis of complexes 1-3

In the ${ }^{1} \mathrm{H}$ NMR spectra in toluene-d8 of complexes $\mathbf{1 - 3}$, the aromatic protons of the $\mathrm{dppBz}$ ligand are observed in the 7.40$6.89 \mathrm{ppm}$ range. Their ${ }^{31} \mathrm{P}\left\{{ }^{1} \mathrm{H}\right\}$ NMR spectra, in the same solvent, display broad signals that appear at 15.32 (1), 15.05 (2) and 16.00 (3) ppm related to both phosphorus atoms present in the diphosphine ligand. The fact that only one signal is detected from the two phosphorus atoms of the neutral three-coordinated gold(I) complex in solution instead of two, based on the presence of the different $\mathrm{P}$-Au distances detected in the X-ray diffraction studies of the solid state (see Crystal structures), could be due to a rapid fluxional oscillation of the perhalophenyl- $\mathrm{Au}(\mathrm{I})$ groups between the two $\mathrm{P}$ centres in solution. In addition, a minor signal around 21-22 ppm is observed in the ${ }^{31} \mathrm{P}\left\{{ }^{1} \mathrm{H}\right\}$ NMR spectra for all complexes. According to previous studies of perhalophenylgold(I) complexes bearing diphosphine ligands, these signals could be assigned to bis chelating cationic species $\left[\mathrm{Au}(\mathrm{dppBz})_{2}\right]^{+}$, in which two ligands are bonded to one gold(I) atom, that coexist with the neutral three-coordinated one in solution. ${ }^{22}$ However, the coexistence of the neutral and the ionic species can only take place in solution. In all cases, pure neutral three-coordinated $\mathrm{Au}(\mathrm{I})$ complexes 1-3 are obtained in the solid state when they are isolated. The presence of neutral $[\mathrm{AuR}(\mathrm{dppBz})]$ (neutral) and ionic $\left[\mathrm{Au}(\mathrm{dppBz})_{2}\right]\left[\mathrm{AuR}_{2}\right]$ was also confirmed for complexes $\mathbf{1}$ and 2 through their ${ }^{19} \mathrm{~F}$ NMR spectra. Thus, there are two groups of signals, the main ones corresponding to the neutral gold(I) complexes, that appear at $-113.91\left(\mathrm{~F}_{\text {orto }}\right),-159.82\left(\mathrm{~F}_{\text {para }}\right)$ and $162.78\left(\mathrm{~F}_{\text {meta }}\right)$ ppm for complex 1 and at $-87.84\left(\mathrm{~F}_{\text {orto }}\right)$ and -117.07 $\left(\mathrm{F}_{\text {para }}\right) \mathrm{ppm}$ for complex 2. The signals related to the anionic fragments $\left[\mathrm{AuR}_{2}\right]^{-}\left(\mathrm{R}=\mathrm{C}_{6} \mathrm{~F}_{5}(\mathbf{1}), \mathrm{C}_{6} \mathrm{Cl}_{2} \mathrm{~F}_{3}(\mathbf{2})\right)$ appear, as weaker signals, at -113.91 ( $\left.\mathrm{F}_{\text {orto }}\right),-159.82\left(\mathrm{~F}_{\text {para }}\right)$ and $-162.78\left(\mathrm{~F}_{\text {meta }}\right)$ ppm (1) and $-87.84\left(\mathrm{~F}_{\text {orto }}\right)$ and $-117.07\left(\mathrm{~F}_{\text {para }}\right)$ ppm (2).

\section{CRYSTAL STRUCTURES}

The slow evaporation of a saturated solution of complexes $\mathbf{2}$ and $\mathbf{3}$ in cyclohexane leads to the formation of single crystals, from which the crystal structures of $\left[\mathrm{Au}\left(\mathrm{C}_{6} \mathrm{Cl}_{2} \mathrm{~F}_{3}\right)(\mathrm{dppBz})\right]$ (2) and $\left[\mathrm{Au}\left(\mathrm{C}_{6} \mathrm{Cl}_{5}\right)(\mathrm{dppBz})\right] \cdot 0.5 \quad \mathrm{C}_{6} \mathrm{H}_{12} \quad\left(\mathbf{3} \cdot 0.5 \quad \mathrm{C}_{6} \mathrm{H}_{12}\right)$ have been determined by X-ray diffraction studies (see Figs 1 and 2).

Complex 2 crystallizes in the $C 2 / c$ space group of the monoclinic system whereas complex $\mathbf{3}$ crystallizes in the $P-1$ space group of the triclinic system with 0.5 molecules of cyclohexane per molecule of the compound. It is worth to note that the $\mathrm{Au}(\mathrm{I})$ atom in the structure of complex 2 exhibits static positional disorder (see SI). Therefore, the structure that will be described in this section and represented in Fig. 1 is the predominant one.

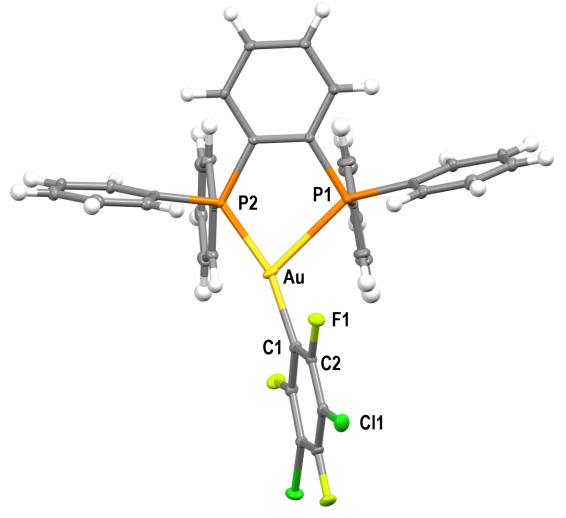

Figure 1. Molecular structure of 2 with the labelling scheme adopted for the atom positions. Selected bond lengths $(\AA)$ and angles $\left({ }^{\circ}\right)$ : $\mathrm{Au}-\mathrm{C}(1)$ 2.071(5), $\mathrm{Au}-\mathrm{P}(1)$ 2.7678(14), $\mathrm{Au}-\mathrm{P}(2)$ 2.2771(12), C(1)-Au-P(1) 118.13(14), C(1)-Au-P(2) 163.99(14), $\mathrm{P}(1)-\mathrm{Au}-\mathrm{P}(2)$ 77.63(4).

The two complexes consist of discrete molecules of stoichiometry [AuR(dppBz)] $\left(\mathrm{R}=\mathrm{C}_{6} \mathrm{Cl}_{2} \mathrm{~F}_{3}(2), \mathrm{C}_{6} \mathrm{Cl}_{5}(3)\right)$, in which the gold center displays a distorted trigonal planar geometry by coordination to the two phosphorus atoms of the bidentate ligand and to the perhalophenyl group. The aryl ligand bonded to gold is 
nearly orthogonal to the central aromatic ring of the diphosphine [dihedral angles $75.2^{\circ}$ in 2 and $77.5^{\circ}$ in $3 \cdot 0.5 \mathrm{C}_{6} \mathrm{H}_{12}$ ] (see Fig $\mathrm{S} 12$ ), and almost parallel to one phenyl ring of each $\mathrm{PPh}_{2}$ group of the diphosphine [dihedral angles 10.6 and $10.8^{\circ}$ in 2 and 6.5 and $15.5^{\circ}$ in $3 \cdot 0.5 \mathrm{C}_{6} \mathrm{H}_{12}$.]

A marked asymmetry in the C-Au-P angles [118.13(14) and $163.99(14)^{\circ}$ in 2 and $116.5(3)$ and $163.8(3)^{\circ}$ in $\left.3 \cdot 0.5 \mathrm{C}_{6} \mathrm{H}_{12}\right]$ is evident. One of them closer to linearity than to a trigonal planar environment in both structures. This asymmetry also affects the Au-P distances [2.7678(14) and 2.2771(12) $\AA$ in 2, and 2.673(2) and $2.302(2) \AA$ in $3 \cdot 0.5 \mathrm{C}_{6} \mathrm{H}_{12}$ ], leading to a non-equivalence of the phosphorus atoms of the $\mathrm{dppBz}$ ligand in the solid state. Thus, the phosphorus involved in the wider $\mathrm{C}-\mathrm{Au}-\mathrm{P}$ angle also displays the shortest Au-P distance as shown in Fig. 3, while the one with a narrower C-Au-P angle is further away from the gold atom. Similar distorted structures have been reported for threecoordinated $\mathrm{Au}(\mathrm{I})$ complexes with rigid diphosphane ligands and halides, ${ }^{23}$ carbene ligands ${ }^{24}$, monoarylphosphane ligands ${ }^{25}$ or bipyridine ligand and aryl/alkylphosphane. ${ }^{26}$ The strong angle and bond length distortions observed for the complexes leading to deviations from the $\mathrm{C}_{2}$ symmetry do not arise from crystal packing effects. Full optimization of a single molecule of complex (2) also gives rise to a symmetry-broken coordination of the Pdonor ligands to $\mathrm{Au}(\mathrm{I})$ (see SI). Similar symmetry-broken structures have recently been reported by Balch and co-workers. ${ }^{26}$ The symmetry-broken coordination of $\mathrm{dppBz}$ to $\mathrm{Au}(\mathrm{I})$ in the studied complexes most likely originates from the mismatch of the bite size of the ligands and lacking orbitals on gold to accept electrons.

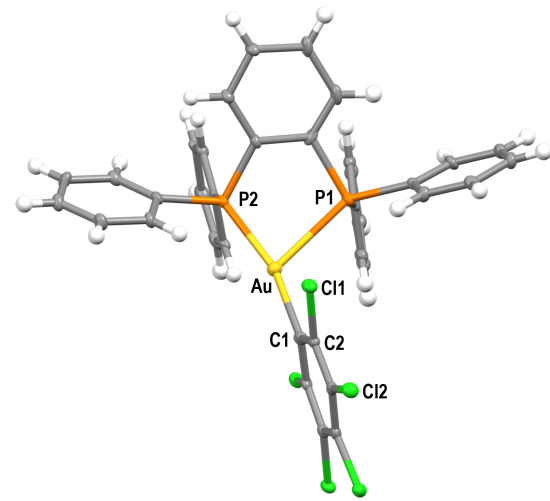

Figure 2. Molecular structure of $3 \cdot 0.5 \mathrm{C}_{6} \mathrm{H}_{12}$ with the labelling scheme adopted for the atom positions. Selected bond lengths $(\AA)$ and angles $\left({ }^{\circ}\right)$ : Au-C(1) 2.070(9), Au-P(1) 2.673(2), Au-P(2) 2.302(2), C(1)-Au-P(1) 116.5(3), C(1)-Au-P(2) 163.8(3), P(1)$\mathrm{Au}-\mathrm{P}(2)$ 79.53(8).

However, the strongest distortion of the trigonal planar environment observed in the crystal structures of 2 and $3 \cdot 0.5$ $\mathrm{C}_{6} \mathrm{H}_{12}$ arises from the small bite angle of the diphosphine (see Fig. 3 ), with P-Au-P angles of 77.63(4) in 2 and $79.53(8)^{\circ}$ in $\mathbf{3} \cdot 0.5$ $\mathrm{C}_{6} \mathrm{H}_{12}$, which are narrower than those found in other threecoordinate gold(I) complexes bearing two monodentate phosphane ligands. $^{27}$
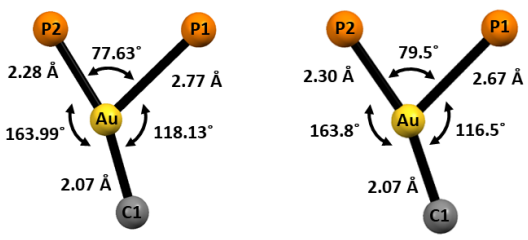

Figure 3. Coordination environment for the gold(I) centres for complexes $\mathbf{2}$ (left) and $\mathbf{3}$ (right).
The coordination of the gold centers does not cause a significant distortion of the ligand, since the distance between the phosphorus atoms in the free $\mathrm{dppBz}$ is $3.165 \AA^{28}$, and only a slight lengthening is observed in 2 and $3 \cdot 0.5 \mathrm{C}_{6} \mathrm{H}_{12}$, showing P-P distances of 3.187 and $3.194 \AA$, respectively. However, a spatial reorganization in the ligand gives rise to the formation of an intramolecular $\pi \cdots \pi$ interaction between two phenyl rings (see SI), with distances between the centroids of 3.755 (2) and 3.811 (3) $\AA$, which is not present in the free ligand.

\section{PHOTOPHYSICAL PROPERTIES AT RT AND 77K}

The absorption spectra in solid state of the perhalophenylgold(I) complexes 1-3 are featureless and very similar. They exhibit intense absorption bands between 200 and $450 \mathrm{~nm}$ (see Fig. 4) and display two maxima at 290 and $330 \mathrm{~nm}$ involving the absorptions related to the metal precursors and the free $\mathrm{dppBz}$ ligand. These absorptions could be assigned to $\pi \rightarrow \pi^{*}$ or $n \rightarrow \pi^{*}$ intraligand transitions for the free diphosphine ligand, or $\pi \rightarrow \pi^{*}$ or $\sigma \rightarrow \pi^{*}$ for the coordinated one, as well as charge transfer transitions involving the perhalophenyl rings and the metal center. The band edges of the new phosphine-gold complexes 1-3 appear at lower energies than the metal precursors (see SI) giving rise to new absorption regions between 370 and $450 \mathrm{~nm}$. These absorptions could be due to charge transfer transitions involving the diphosphine ligand and the perhalophenyl gold groups.

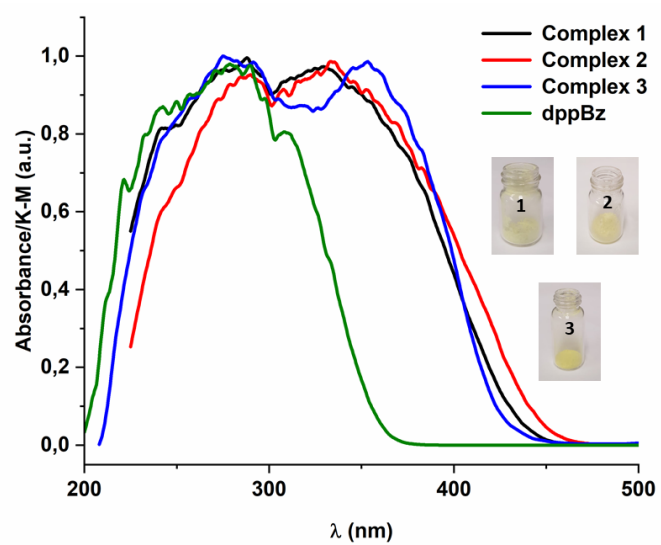

Figure 4. UV-vis absorption spectra in solid states of complexes $\left[\mathrm{Au}\left(\mathrm{C}_{6} \mathrm{~F}_{5}\right)(\mathrm{dppBz})\right](\mathbf{1})$ (black), $\quad\left[\mathrm{Au}\left(\mathrm{C}_{6} \mathrm{Cl}_{2} \mathrm{~F}_{3}\right)(\mathrm{dppBz})\right](2) \quad$ (red) $\left[\mathrm{Au}\left(\mathrm{C}_{6} \mathrm{Cl}_{5}\right)(\mathrm{dppBz})\right](3)$ (blue), and the free dppBz (green).

The three complexes $[\mathrm{AuR}(\mathrm{dppBz})]\left(\mathrm{R}=\mathrm{C}_{6} \mathrm{~F}_{5}(\mathbf{1}), \mathrm{C}_{6} \mathrm{Cl}_{2} \mathrm{~F}_{3}(\mathbf{2})\right.$, $\mathrm{C}_{6} \mathrm{Cl}_{5}$ (3)) display an intense luminescent yellow emission when they are irradiated with UV-vis light (see Fig. 5). Thus, one emission band located at $560 \mathrm{~nm}(\Phi=0.29)(1), 545 \mathrm{~nm}(\Phi=$ $0.16)$ (2) and $555 \mathrm{~nm}(\Phi=0.11)$ (3) is observed when the complexes are excited in the 300-400 $\mathrm{nm}$ range. The emission lifetimes obtained for complexes 1-3 (see SI) are in the microsecond range with values of $8.8 \mu \mathrm{s}$ (1), $20.8 \mu \mathrm{s}(\mathbf{2}), 23.8 \mu \mathrm{s}$ (3). When the temperature is lowered to $77 \mathrm{~K}$, the emission bands are red shifted for the three complexes, leading to new emission maxima centered at 575 (1), 570 (2) and $585 \mathrm{~nm}$ (3). However, this is not the only significant effect due to the lowering of the temperature, but a considerable increase in the lifetimes is also observed reaching values of $41.8 \mu$ s (1), $72.8 \mu$ s (2), $61.7 \mu$ s (3). With these data and the corresponding computational studies (vide infra) we can assign the origin of the emissive behavior to a metal-ligand to ligand charge transfer transition (MLLCT). 

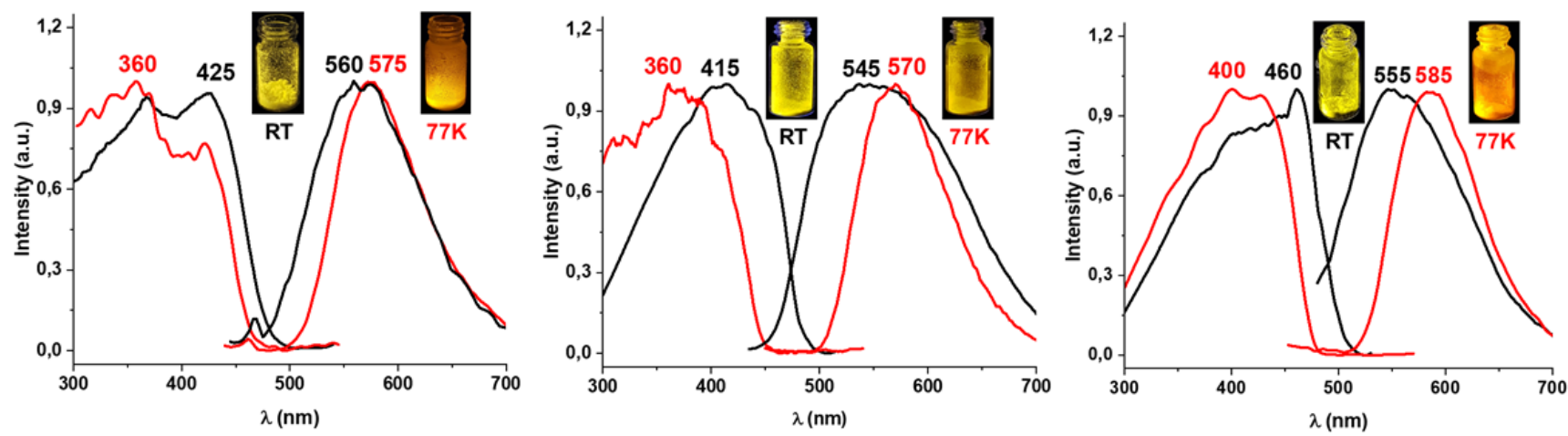

Figure 5. Excitation and emission spectra in solid state of complexes $\left[\mathrm{Au}\left(\mathrm{C}_{6} \mathrm{~F}_{5}\right)(\mathrm{dppBz})\right](\mathbf{1})(\mathrm{left}),\left[\mathrm{Au}\left(\mathrm{C}_{6} \mathrm{Cl}_{2} \mathrm{~F}_{3}\right)(\mathrm{dppBz})\right](2)(\mathrm{center})$ and $\left[\mathrm{Au}\left(\mathrm{C}_{6} \mathrm{Cl}_{5}\right)(\mathrm{dppBz})\right](3)$ (right) at room temperature (black) and at $77 \mathrm{~K}$ (red).

Hence, the significant reduction in the emission lifetimes detected at room temperature, the blue-shift when the temperature increases from $77 \mathrm{~K}$ to $300 \mathrm{~K}$, and the important SOC promoted by the gold(I) centers that makes the triplet excited states accessible are indicative of possible TADF emitters.

\section{THERMALLY ACTIVATED DELAYED FLUORESCENCE STUDIES}

In order to confirm the TADF emission mechanism, the emission spectra and the emission lifetimes were collected in a temperature range of 77 to $300 \mathrm{~K}$ for each complex. The three complexes display a similar photophysical behavior and, we observed a redshift in the emission spectra of 1-3 complexes by cooling.

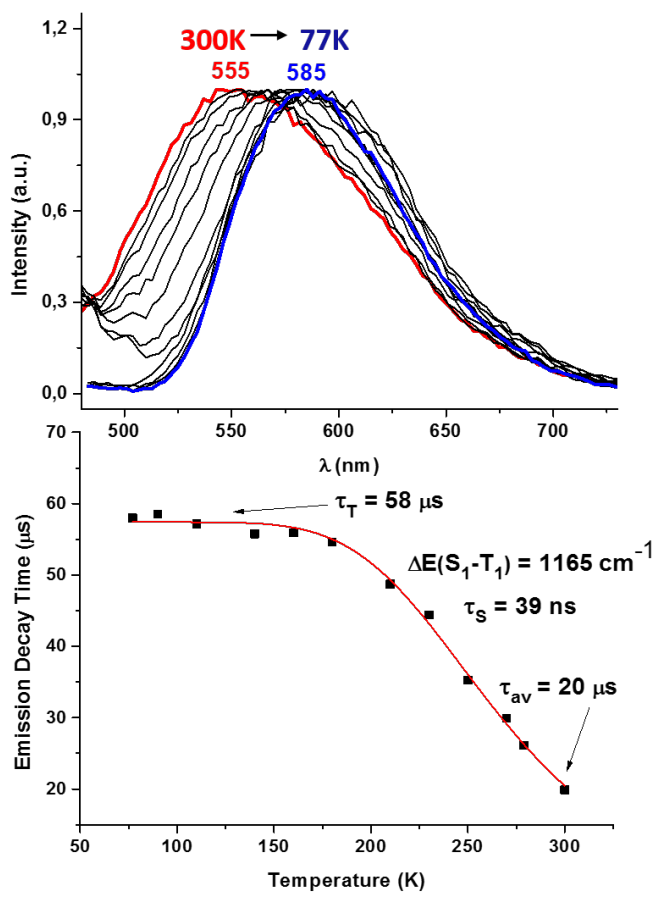

Figure 6. The temperature-dependent change of the corrected emission spectra (up) and the emission decay times (bottom) for complex 3 .

The temperature dependent changes of the emission spectra and the decay time measured for $\left[\mathrm{Au}\left(\mathrm{C}_{6} \mathrm{Cl}_{5}\right)(\mathrm{dppBz})\right](3)$ are shown in the upper and lower graphs of Fig. 6, respectively. The analogous results for complexes 1 and $\mathbf{2}$ are reported in Figs S17-S18 of the
Supporting Information (SI). The profiles obtained for the emission decay lifetimes as a function of the temperature indicate a fast thermal equilibrium between the $T_{1}$ and $S_{1}$ states. The emission decay time $\tau$ can therefore be expressed by a Boltzmanntype equation: ${ }^{23,29}$

$$
\boldsymbol{\tau}_{\mathrm{av}}=\frac{3+\exp \left(-\Delta \mathbf{E}\left(\mathbf{S}_{1}-\mathbf{T}_{1}\right) / \mathbf{k}_{\mathrm{B}} \mathbf{T}\right)}{3 / \boldsymbol{\tau}_{\mathrm{T}}+1 / \boldsymbol{\tau}_{\mathbf{S}} \exp \left(-\Delta \mathbf{E}\left(\mathbf{S}_{1}-\mathbf{T}_{\mathbf{1}}\right) / \mathbf{k}_{\mathbf{B}} \mathbf{T}\right)}
$$

where $\mathrm{k}_{\mathrm{B}}$ denotes the Boltzmann constant. $\tau_{\mathrm{T}}$ and $\tau_{\mathrm{S}}$ represent the phosphorescence $\left(\mathrm{T}_{1} \rightarrow \mathrm{S}_{0}\right)$ and prompt fluorescence $\left(\mathrm{S}_{1} \rightarrow \mathrm{S}_{0}\right)$ decay times without thermal activation. ${ }^{28}$

We obtained the $\Delta \mathrm{E}\left(\mathrm{S}_{1}-\mathrm{T}_{1}\right)$ energy difference and the fluorescence decay times by fitting the equation to the measured emission decay times in Fig. 6 and in Figs S17, S18 of the SI and by using $\tau_{\mathrm{T}}$ values of 35,73 and $58 \mu$ s for $\mathbf{1}, \mathbf{2}$ and $\mathbf{3}$, respectively, which were measured at $\mathrm{T}=77 \mathrm{~K}$. The obtained $\Delta \mathrm{E}\left(\mathrm{S}_{1}-\mathrm{T}_{1}\right)$ values for the three complexes are $656(\mathbf{1}), 966(2), 1165(3) \mathrm{cm}^{-1}$.

The fitted values for $\Delta \mathrm{E}\left(\mathrm{S}_{1}-\mathrm{T}_{1}\right)$ agree well with the experimental $\Delta \mathrm{E}\left(\mathrm{S}_{1}-\mathrm{T}_{1}\right)$ values of $466(\mathbf{1}), 805(2), 925(3) \mathrm{cm}^{-1}$, which were deduced from the difference in the wave lengths of the peak maxima measured at $300 \mathrm{~K}$ (almost TADF) and $77 \mathrm{~K}$ (almost phosphorescence). ${ }^{23}$ The experimental data confirm that complexes 1-3 exhibit delayed fluorescence at room temperature.

\section{COMPUTATIONAL STUDIES}

In order to better understand the TADF properties of the studied complexes, we performed calculations at different levels of theory on a model system of the $\left[\mathrm{Au}\left(\mathrm{C}_{6} \mathrm{Cl}_{2} \mathrm{~F}_{3}\right)(\mathrm{dppBz})\right](2)$ complex. The results of the calculations are summarized in Table 1.

Table 1. The excitation energies ( $\mathrm{E}$ in $\mathrm{cm}^{-1}$ and $\mathrm{eV}$ in parentheses) calculated at the XMC-QDPT2 level are compared to experimental data. Spin-orbit coupling matrix element ( $\left\langle\mathrm{S}_{1}\left|\mathrm{H}_{\mathrm{SO}}\right| \mathrm{T}_{1}\right\rangle$ in $\left.\mathrm{cm}^{-1}\right)$, the rate constants for intersystem crossing $\left(k_{I S C}\left(\mathrm{~S}_{1} \rightarrow\right.\right.$ $\left.\mathrm{T}_{1}\right)$ ) and the rate constants for reversed intersystem crossing $\left(k_{\text {RISC }}\left(\mathrm{T}_{1} \rightarrow \mathrm{S}_{1}\right)\right)$ are also reported.

\begin{tabular}{|c|c|c|c|c|c|}
\hline & \multicolumn{2}{|c|}{$\mathrm{E}($ Calcd $)$} & $\left\langle\mathrm{S}_{1}\left|\mathrm{H}_{\mathrm{So}}\right| \mathrm{T}_{1}\right\rangle$ & $\begin{array}{c}k_{I S C} \\
\left(S_{1} \rightarrow T_{1}\right)\end{array}$ & $\begin{array}{c}k_{R I S C} \\
\left(\mathrm{~T}_{1} \rightarrow \mathrm{S}_{1}\right)\end{array}$ \\
\hline State & $S_{1}$ & $\mathrm{~T}_{1}$ & & & \\
\hline \multirow[t]{2}{*}{ Value } & $\begin{array}{l}11050 \\
(1.37)\end{array}$ & $\begin{array}{c}9840 \\
(1.22)\end{array}$ & 4 & $7 \cdot 10^{9} \mathrm{~s}^{-1}$ & $2 \cdot 10^{7} \mathrm{~s}^{-1}$ \\
\hline & \multicolumn{2}{|c|}{$E(E x p)$} & & & \\
\hline State & $\mathrm{S}_{1}$ & $\mathrm{~T}_{1}$ & & & \\
\hline Value & $\begin{array}{l}18309 \\
(2.27)\end{array}$ & $\begin{array}{l}17502 \\
(2.17)\end{array}$ & & $1 \cdot 10^{10} \mathrm{~s}^{-1}$ & $2.2 \cdot 10^{8} \mathrm{~s}^{-1}$ \\
\hline
\end{tabular}


The calculated and measured energy difference between the $S_{1}$ and $\mathrm{T}_{1}$ computed states in Table 1 is $1200 \mathrm{~cm}^{-1}(0.15 \mathrm{eV})$. Thermally activated delayed fluorescence (TADF) occurs when the energy gap between the $S_{1}$ and $T_{1}$ states is about $1000 \mathrm{~cm}^{-1}$ according to previous studies. ${ }^{30-33}$ The calculations yielded a rate constant for reverse intersystem crossing $\left(k_{\text {RISC }}\left(\mathrm{T}_{1} \rightarrow \mathrm{S}_{1}\right)\right)$ of $2.2 \cdot 10^{8} \mathrm{~s}^{-1}$ and a rate constant for intersystem crossing $\left(k_{I S C}\left(\mathrm{~T}_{1} \rightarrow \mathrm{S}_{0}\right)\right)$ of $10 \mathrm{~s}^{-1}$. The calculated spin-orbit coupling matrix element ( $\left.\left\langle\mathrm{T}_{1}\left|\mathrm{H}_{\mathrm{SO}}\right| \mathrm{S}_{0}\right\rangle\right)$ is $20 \mathrm{~cm}^{-1}$. The calculations strongly underestimated the de-excitation energies from the $S_{1}$ and $T_{1}$ states to the ground state, because in the present optimization of the molecular structure of a single molecule, the molecular structure can freely relax, whereas in the solid state large structural changes are not possible due to the presence of the neighboring molecules. More accurate $k_{R I S C}\left(\mathrm{~T}_{1} \rightarrow \mathrm{S}_{1}\right), k_{I S C}\left(\mathrm{~S}_{1} \rightarrow \mathrm{T}_{1}\right)$ and $k_{I S C}\left(\mathrm{~T}_{1} \rightarrow \mathrm{S}_{0}\right)$ rate constants can be obtained by using experimental values for the excitation energies of the $T_{1}$ and $S_{1}$ states and calculated values for the spin-orbit coupling matrix elements $\left(\left\langle\mathrm{T}_{1}\left|\mathrm{H}_{\mathrm{SO}}\right| \mathrm{S}_{0}\right\rangle\right.$ and \langle $\left.\left.\mathrm{S}_{1}\left|\mathrm{H}_{\mathrm{SO}}\right| \mathrm{T}_{1}\right\rangle\right)$. We obtained a $k_{I S C}\left(\mathrm{~T}_{1} \rightarrow \mathrm{S}_{0}\right)<<10^{-3} \mathrm{~s}^{-1}$ when assuming that the phosphorescence time constant $t$ is $76 \mu \mathrm{s}$ corresponding to a rate constant of $13 \mathrm{~s}^{-1}$, and that the rate constant for internal conversion $k_{I C}\left(\mathrm{~T}_{1} \rightarrow \mathrm{S}_{0}\right)$ is about $2 \cdot 10^{3} \mathrm{~s}^{-1}$, which is typical for gold complexes. ${ }^{34}$ Internal conversion can occur from the $\mathrm{T}_{1}$ state to the singlet ground state, because the $T_{1}$ state is a spin-mixed state consisting of a mixture of singlet and triplet wave functions due to spin-orbit coupling as discussed in ref. 35. Reversed intersystem crossing $k_{R I S C}\left(\mathrm{~T}_{1} \rightarrow \mathrm{S}_{1}\right)$ will then be the main intramolecular deactivation channel of the $\mathrm{T}_{1}$ state. Our calculations combined with experimental data show that TADF occurs because of the small energy difference of between the $S_{1}$ and $T_{1}$ states of $1200 \mathrm{~cm}^{-1}$. The rate constant of the reversed intersystem crossing $k_{\text {RISC }}\left(\mathrm{T}_{1} \rightarrow \mathrm{S}_{1}\right)$ of about $10^{8} \mathrm{~s}^{-1}$ is much larger than for the other intramolecular channels of the $\mathrm{T}_{1}$ deactivation.

The $\mathrm{S}_{1}$ state is formed from the $\mathrm{S}_{0}$ state by a formal electronic transition from the highest occupied molecular orbital (HOMO) to the lowest unoccupied molecular orbital (LUMO) with a weight of 0.67 . The HOMO $\rightarrow$ LUMO excitation occurs from the HOMO located on Au-P to the LUMO located on the ligand part. The $\mathrm{T}_{1}$ is also mainly a $\mathrm{HOMO} \rightarrow$ LUMO electronic transition with a weight of 0.69 . Our calculation shows that the $\mathrm{S}_{0}$ is a closed-shell singlet reference state with a weight of 0.95 (see Fig. 7).
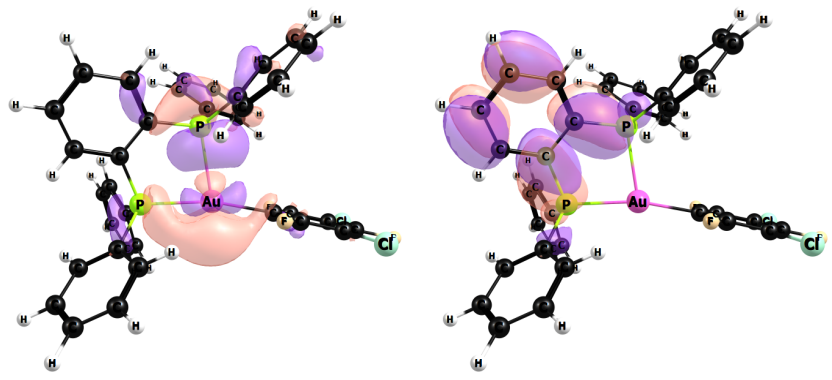

Figure. 7. The frontier molecular orbitals HOMO (left) and LUMO (right) calculated at the CASSCF level of theory.

\section{CONCLUSIONS}

We have reported a new class of perhalophenyl-gold(I) diphoshine complexes with distorted structural arrangement in the solid state that precludes the emission from metal-centred (MC) excited states and strongly favors emission from metal-ligand-toligand charge transfer (MLLCT) excited states. Due to the significant spin-orbit coupling (SOC) of the gold(I) centres, the structural rigidity of the 1-3 complexes and the small energy difference between the $S_{1}$ and $T_{1}$ states $\left(\Delta E\left(S_{1}-T_{1}\right)\right)$, which was obtained both experimentally and computationally, these complexes display very interesting TADF emitting properties.
The rate constants for intersystem crossing (ISC) and reverse intersystem crossing (RISC) calculated at high level of theory agree well with experimental data. The calculations that provided important information for understanding the TADF mechanism of the studied complexes are a useful tool for the design of TADF molecular systems and studies of photophysical processes. The computational studies corroborate conclusions drawn in the experimental part of this work. Future ligand variations as well as synthesis of homo- and heteropolynuclear $\mathrm{Au}(\mathrm{I})$-based systems will allow us to study in-depth the tuning of the TADF property of these molecular systems.

\section{EXPERIMENTAL SECTION}

General. The starting materials $[\mathrm{AuR}(\mathrm{tht})]\left(\mathrm{R}=\mathrm{C}_{6} \mathrm{~F}_{5}, \mathrm{C}_{6} \mathrm{Cl}_{2} \mathrm{~F}_{3}\right.$, $\left.\mathrm{C}_{6} \mathrm{Cl}_{5}\right)^{36}$ were prepared as described in the literature. The ligand 1,2-bis(diphenylphosphino)benzene was obtained from SigmaAldrich and used as received. All solvents used for the synthesis of the new compounds were obtained from commercial sources and were used without further purification.

Instrumentation. Infrared spectra were recorded in the 4000 $500 \mathrm{~cm}^{-1}$ range on a PerkinElmer FT-IR Spectrum Two with an ATR accessory. $\mathrm{C}$ and $\mathrm{H}$ analyses were carried out with a PerkinElmer 240C microanalyzer. ESI-MS spectra were obtained with a Bruker MicroTOF-Q spectrometer with ESI ionization source. ${ }^{31} \mathrm{P}\left\{{ }^{1} \mathrm{H}\right\},{ }^{19} \mathrm{~F}$ and ${ }^{1} \mathrm{H}$ NMR experiments were recorded on a Bruker ARX 300 in $\mathrm{d} 8$-toluene. Chemical shifts are quoted relative to $\mathrm{H}_{3} \mathrm{PO}_{4}\left({ }^{31} \mathrm{P}\right.$, external $), \mathrm{CFCl}_{3}\left({ }^{19} \mathrm{~F}\right.$, external $)$ and $\mathrm{SiMe}_{4}\left({ }^{1} \mathrm{H}\right.$, external). Diffuse reflectance UV-vis spectra of pressed powder samples diluted with $\mathrm{KBr}$ were recorded on a Shimadzu (UV3600 spectrophotometer with a Harrick Praying Mantis accessory) and recalculated following the Kubelka-Munk function. Excitation and emission spectra in the solid state as well as lifetime measurements were recorded with a Jobin-Yvon Horiba Fluorolog 3-22 Tau-3 spectrofluorimeter.

Synthesis Complexes [AuR(dppBz)] ( $R=C_{6} F_{5}(1), C_{6} C l_{2} F_{3}$ (2) and $\mathrm{C}_{6} \mathrm{Cl}_{5}$ (3)). To a dichloromethane solution $(20 \mathrm{ml})$ of $\left[\mathrm{Au}\left(\mathrm{C}_{6} \mathrm{~F}_{5}\right)(\mathrm{tht})\right](0.200 \mathrm{~g}, 0.442 \mathrm{mmol})(\mathbf{1}),\left[\mathrm{Au}\left(\mathrm{C}_{6} \mathrm{Cl}_{2} \mathrm{~F}_{3}\right)(\mathrm{tht})\right]$ $(0.200 \mathrm{~g}, 0.413 \mathrm{mmol})(2)$ or $\left[\mathrm{Au}\left(\mathrm{C}_{6} \mathrm{Cl}_{5}\right)(\mathrm{tht})\right](0.200 \mathrm{~g}, 0.375$ mmol) (3) was added 1,2-Bis(diphenylphosphino)benzene (dppBz) (0.198 g, $0.442 \mathrm{mmol}$ (1), $0.185 \mathrm{~g}, 0.413 \mathrm{mmol}$ (2) and $0.167 \mathrm{~g}, 0.375 \mathrm{mmol}(\mathbf{3}))$ in a $1: 1 \mathrm{molar}$ ratio. After 30 minutes of stirring at room temperature the solvent was evaporated under vacuum to $c a$. $5 \mathrm{ml}$. Finally, addition of $n$-hexane $(15 \mathrm{~mL})$ led to precipitation of products $1(0.287 \mathrm{~g}, 0.354 \mathrm{mmol}), 2(0.237 \mathrm{~g}$, $0.281 \mathrm{mmol})$ and $3(0.244 \mathrm{~g}, 0.273 \mathrm{mmol})$ all of them as yellow solids. Yield: $80 \%$ (1), 68\% (2), 73\% (3).

Experimental data for 1: Elemental analysis (\%) calcd for 1: $\left(\mathrm{C}_{36} \mathrm{H}_{24} \mathrm{P}_{2} \mathrm{AuF}_{5}\right): \mathrm{C}, 53.35 ; \mathrm{H}, 2.98$. Found: C,53.81; H, $2.98 .{ }^{1} \mathrm{H}$ $\left(298 \mathrm{~K}\right.$, toluene-d8): $\delta 7.42-7.00\left(\mathrm{~m}, 24 \mathrm{H}, \mathrm{H}_{\mathrm{Ar}}\right) .{ }^{19} \mathrm{~F}(298 \mathrm{~K}$, toluene-d8): $\delta-162.78\left(\mathrm{~m}, 2 \mathrm{~F}, \mathrm{~F}_{\mathrm{m}}\right), \delta-159.82\left(\mathrm{t}, 1 \mathrm{~F}, \mathrm{~F}_{\mathrm{p}}\right), \delta-$ $113.91\left(\mathrm{~m}, 2 \mathrm{~F}, \mathrm{~F}_{\mathrm{o}}\right) .{ }^{31} \mathrm{P}\left\{{ }^{1} \mathrm{H}\right\}(298 \mathrm{~K}$, toluene-d8): $\delta 15.32(\mathrm{~m}, 2 \mathrm{P})$. MS(ESI-): $\mathrm{m} / \mathrm{z} 530.96 \quad\left[\mathrm{Au}\left(\mathrm{C}_{6} \mathrm{~F}_{5}\right)_{2}\right]^{-}, \quad \operatorname{ESI}(+): \mathrm{m} / \mathrm{z} 811.09$ $\left[\mathrm{C}_{36} \mathrm{H}_{25} \mathrm{P}_{2} \mathrm{AuF}_{5}\right]^{+} ; 1089.23\left[\mathrm{C}_{60} \mathrm{H}_{48} \mathrm{P}_{4} \mathrm{Au}\right]^{+}$. ATR-IR: $v$ 496, 512, $543 \mathrm{~cm}^{-1}$ (dppBz); v 798, 952, $1635 \mathrm{~cm}^{-1}\left(\mathrm{Au}-\left(\mathrm{C}_{6} \mathrm{~F}_{5}\right)\right.$ ).

Experimental data for 2: Elemental analysis (\%) calcd for 2: $\left(\mathrm{C}_{36} \mathrm{H}_{24} \mathrm{P}_{2} \mathrm{AuCl}_{2} \mathrm{~F}_{3}\right)$ : C, 51.27; H, 2.87. Found: $\mathrm{C}, 51.31 ; \mathrm{H}, 2.78$. ${ }^{1} \mathrm{H}\left(298 \mathrm{~K}\right.$, toluene-d8): $\delta 7.33-6.89\left(\mathrm{~m}, 24 \mathrm{H}, \mathrm{H}_{\mathrm{Ar}}\right) .{ }^{19} \mathrm{~F}(298 \mathrm{~K}$, toluene-d8): $\delta-117.07\left(\mathrm{~s}, 1 \mathrm{~F}, \mathrm{~F}_{\mathrm{p}}\right), \delta-87.84\left(\mathrm{~m}, 2 \mathrm{~F}, \mathrm{~F}_{\mathrm{o}},\right) .{ }^{31} \mathrm{P}\left\{{ }^{1} \mathrm{H}\right\}$ (298K, toluene-d8): $\delta 15.05(\mathrm{~m}, 2 \mathrm{P}) . \mathrm{MS}(\mathrm{ESI}-): \mathrm{m} / \mathrm{z} 596.83$ $\left[\mathrm{Au}\left(\mathrm{C}_{6} \mathrm{Cl}_{2} \mathrm{~F}_{3}\right)_{2}\right]^{-}, \mathrm{ESI}(+): \mathrm{m} / \mathrm{z} 843.03\left[\mathrm{C}_{36} \mathrm{H}_{25} \mathrm{P}_{2} \mathrm{AuCl}_{2} \mathrm{~F}_{3}\right]^{+} ; 1089.23$ $\left[\mathrm{C}_{60} \mathrm{H}_{48} \mathrm{P}_{4} \mathrm{Au}\right]^{+}$. ATR-IR: $v$ 490, 514, $533 \mathrm{~cm}^{-1}$ (dppBz); $v$ 771, $1564,1579,1592 \mathrm{~cm}^{-1}\left(\mathrm{Au}-\left(\mathrm{C}_{6} \mathrm{Cl}_{2} \mathrm{~F}_{3}\right)\right)$.

Experimental data for 3: Elemental analysis (\%) calcd for 3: $\left(\mathrm{C}_{36} \mathrm{H}_{24} \mathrm{P}_{2} \mathrm{AuCl}_{5}\right)$ : C, 48.43; H, 2.71. Found: $\mathrm{C}, 47.99 ; \mathrm{H}, 3.04 .{ }^{1} \mathrm{H}$ (298K, toluene-d8): $\delta 7.38-6.90\left(\mathrm{~m}, 24 \mathrm{H}, \mathrm{H}_{\mathrm{Ar}}\right) .{ }^{31} \mathrm{P}\left\{{ }^{1} \mathrm{H}\right\}(298 \mathrm{~K}$, toluene-d8): $\delta 16.00$ (s, 2P). MS(ESI-): m/z $694.64\left[\mathrm{Au}\left(\mathrm{C}_{6} \mathrm{Cl}_{5}\right)_{2}\right]^{-}$, $\mathrm{ESI}(+): \mathrm{m} / \mathrm{z} 890.94\left[\mathrm{C}_{36} \mathrm{H}_{25} \mathrm{P}_{2} \mathrm{AuCl}_{5}\right]^{+} ; 1089.23\left[\mathrm{C}_{60} \mathrm{H}_{48} \mathrm{P}_{4} \mathrm{Au}\right]^{+}$. 
ATR-IR: $v$ 491, 515, $530 \mathrm{~cm}^{-1}(\mathrm{dppBz}) ; v 620,836 \mathrm{~cm}^{-1}(\mathrm{Au}-$ $\left.\left(\mathrm{C}_{6} \mathrm{Cl}_{5}\right)\right)$.

Crystallography. Crystals were mounted in inert oil on glass fibers and transferred to the cold gas stream of a Bruker APEX-II CCD diffractometer equipped with an Oxford Instruments lowtemperature attachment. Data were collected using monochromated MoKa radiation $(\lambda=0.71073 \AA)$. Scan type: $\omega$ and $\varphi$. Absorption corrections: semiempirical (multiple scans). The structures were solved by intrinsic fazing refined on $\mathrm{F}^{2}$ using the program SHELXLT. ${ }^{37}$ All non-hydrogen atoms were refined anisotropically. Hydrogen atoms were included using a riding model.

Computational Details. The molecular structure of the lowest excited triplet state $\left(\mathrm{T}_{1}\right)$ was optimized at the density functional theory (DFT) level using the $\mathrm{B}^{2} \mathrm{LYP}^{38}$ functional and the $6-31 \mathrm{G}(\mathrm{d}, \mathrm{p})^{39}$ basis sets. The 60 core electrons of Au were replaced with an effective core potential (ECP). ${ }^{40}$ The spin-orbit coupling matrix elements $\left\langle\mathrm{S}_{1}\left|\mathrm{H}_{\mathrm{SO}}\right| \mathrm{T}_{1}\right\rangle$ between the first excited singlet state $\left(\mathrm{S}_{1}\right)$ and the lowest triplet state $\left(\mathrm{T}_{1}\right)$ as well as between $T_{1}$ and the ground state $\left(\mathrm{S}_{0}\right)$ were calculated at the complete active space consistent self field (CASSCF) level using the GAMESS-US program. ${ }^{41,42}$ Excitation energies were calculated at the extended multi-configuration quasi-degenerate perturbation theory at the second order (XMC-QDPT2) level. ${ }^{43}$ The XMC-QDPT2 calculations and the geometry optimization were performed using the Firefly software. ${ }^{44}$ The state-averaged CASSCF wave function was constructed from the four lowest electronic states obtained in a CASSCF calculation using an active space that consisted of four electrons in four molecular orbitals (MOs). We chose an active space with the 4 electrons in 4 MOs based on preliminary TDDFT calculations, which showed that the $\mathrm{S}_{0} \rightarrow \mathrm{S}_{1}$ and $\mathrm{S}_{0} \rightarrow \mathrm{T}_{1}$ transitions are dominated by excitations from HOMO and HOMO-1 to LUMO and LUMO+1HOMO is the highest occupied molecular orbital and LUMO is the lowest unoccupied molecular orbital. This active space is balanced based on the fast convergence of the optimization of the CASSCF wave function.

\section{ASSOCIATED CONTENT}

Supporting Information.

The Supporting Information as noted in the text is available free of charge on the ACS Publications website at DOI: $\mathrm{xxxxx}$ /acs.inorgchem.yyyyy. It contains characterization by IR (Figs S1-S3) and NMR (Figs S4-S11) spectroscopy; calculated isotopic patterns for MS-ESI data (Figs S12-S14); tables containing details about the data collection and refinement for 2 and 3.0.5 $\mathrm{C}_{6} \mathrm{H}_{12}$ (Table S1); molecular structures (Figs S15-S16); absorption spectra of 1-3 as compared to the spectra of the gold(I) precursors (Figs S17-S19); graphs showing TADF results for 1 and 2 (Figs S20-S21); lifetimes for 1 and 2 (Figs S22-S24) and ground state DFT optimized model system $\mathbf{2}$ in the gas phase (Fig S25).

\section{Accession Codes}

CCDC 2014241 (2) and $2014240\left(\mathbf{3} \cdot 0.5 \mathrm{C}_{6} \mathrm{H}_{12}\right)$ contain the supplementary crystallographic data for this paper. These data can be obtained free of charge via www.ccdc.cam.ac.uk/data_request/cif, or by emailing data request@ccdc.cam.ac.uk, or by contacting The Cambridge Crystallographic Data Center, 12 Union Road, Cambridge CB2 1EZ, UK; fax: +44 1223336033 .

\section{AUTHOR INFORMATION}

\section{Corresponding Author}

*E-mail: josemaria.lopez@unirioja.es maria.rodriguez@unirioja.es
ORCID

José M. López-de-Luzuriaga: 0000-0001-5767-8734

Miguel Monge: 0000-0002-9672-8279

M. Elena Olmos: 0000-0001-8890-8977

María Rodríguez-Castillo: 0000-0002-9450-2305

Inés Soldevilla: 0000-0001-7885-387X

Dage Sundholm: 0000-0002-2367-9277

Rashid R. Valiev: 0000-0002-2088-2608

\section{FUNDING SOURCES}

No competing financial interests have been declared.

\section{ACKNOWLEDGMENT}

We thank the D.G.I. MINECO/FEDER (project number PID2019104379RB-C22 (AEI/FEDER, UE)) and the EC support through the FEDER project NUTRIA (EFA 356/19) for financial support. The Academy of Finland supported this work through projects 314821 and 325369. CSC - the Finnish IT Center for Science and the Finnish Grid and Cloud Infrastructure (persistent identifier urn:nbn:fi:research-infras-2016072533) are acknowledged for computer time.

\section{REFERENCES}

(1) (a) Yersin, H. (Ed.), Highly efficient OLEDs with phosphorescent materials, Wiley-VCH, Weinheim, 2008; (b) Zampetti, A.; Minotto, A.; Cacialli, F. Near-Infrared (NIR) organic light-emitting diodes (OLEDs): Challenges and Opportunities. Adv. Funct. Mater. 2019, 29, 1807623; (c) Zhang, Q.-C.; Xiao, H.; Zhang, X.; Xu, L.-J.; Chen, Z.-N. Luminescent oligonuclear metal complexes and the use in organic light-emitting diodes. Coord. Chem. Rev., 2018, 378, 121-133

(2) Yersin, H.; Rausch, A. F.; Czerwieniec, R.; Hofbeck, T.; Fischer, T. The triplet state of organo-transition metal compounds. Triplet harvesting and singlet harvesting for efficient OLEDS. Coord. Chem. Rev. $2011,255,2622-2652$.

(3) (a) Goodenough, J. B. Spin-orbit-coupling effects in transitionmetal compounds. Phys. Rev. 1968, 171, 466-479; (b) Mori, K.; Goumans, T. P. M.; van Lenthe, E.; Wang, F. Predicting phosphorescent lifetimes and zero-field splitting of organometallic complexes with timedependent density functional theory including spin-orbit coupling. Phys. Chem. Chem. Phys., 2014, 16, 14523-14530.

(4) Blasse, G.; Mcmillin, D. R. On the luminescence of bis (triphenylphosphine) phenanthroline copper(I). Chem. Phys. Lett., 1980, $70,1-3$.

(5) Zink, D. M.; Bächle, M., Baumann, T.; Nieger, M.; Kühn M.; Wang, C.; Klopper, W.; Monkowius, U.; Hofbeck, T.; Yersin, H.; Bräse, S. Synthesis, structure, and characterization of dinuclear copper(I) halide complexes with $\mathrm{P}^{\wedge} \mathrm{N}$ ligands featuring exciting photoluminescence properties. Inorg. Chem., 2013, 52, 2292-2305.

(6) Chakkaradhari,G.; Eskelinen, T.; Degbe, C.; Belyaev, A.; Melnikov, A. S.; Grachova, E. V.; Tunik, S. P.; Hirva, P.; Koshevoy, I. O. Oligophosphine-thiocyanate Copper(I) and Silver(I) Complexes and Their Borane Derivatives Showing Delayed Fluorescence. Inorg. Chem., $2019,58,3646-3660$.

(7) Li, G.; Zhu, Z.-Q.; Chen, Q.; Li, J. Metal complex based delayed fluorescent materials. Organic Electronics, 2019, 69, 135-152.

(8) Ziolo, R. F.; Lipton, S.; Dori Z. The photoluminescence of phosphine complexes of $\mathrm{d}^{10}$ metals. Chem. Commun., 1970, 1124-1125.

(9) Yam, V. W.-W.; Au, V. K.-M.; Leung, S. Y.-L. Light-Emitting Self-Assembled Materials Based on $\mathrm{d}^{8}$ and $\mathrm{d}^{10}$ Transition Metal Complexes. Chem. Rev. 2015, 115, 7589-7728.

(10) Blake, A. J.; Donamaría, R.; Lippolis, V.; López-de-Luzuriaga, J. M.; Monge, M.; Olmos, M. E.; Seal, A.; Weinstein, J. A. Unequivocal 
experimental evidence of the relationship between emission energies and aurophilic interactions. Inorg. Chem. 2019, 58, 4954-4961.

(11) Yam, V. W.-W.; Cheng, E. C.-C. Highlights on the recent advances in gold chemistry-a photophysical perspective. Chem. Soc. Rev., 2008, 1806-1813.

(12) (a) Fernández. E. J.; Laguna, A.; López-de-Luzuriaga, J. M. Luminiscence in complexes with $\mathrm{Au}(\mathrm{I})-\mathrm{Tl}(\mathrm{I})$ interactions. Coord. Chem. Rev. 2005, 249, 1423-1433; (b) Fernández. E. J.; Laguna, A.; López-deLuzuriaga, J. M. Gold-heterometal complexes. Evolution of a new class of luminescent materials. Dalton Trans., 2007, 1969-1981.

(13) Osawa, M.; Kawata, I.; Ishii, R.; Igawa, S.; Hashimoto, M.; Hoshino, M. Application of neutral d10 coinage metal complexes with an anionic bidentate ligand in delayed fluorescence-type organic lightemitting diodes. J. Mater. Chem. C, 2013, 1, 4375-4383.

(14) Bizarri, C.; Hundemer, F.; Busch, J.; Bräse, S. Triplet emitters versus TADF emitters in OLEDs. A comparative study. Polyhedron 2018 , 140, 51-66.

(15) Lima, J. C.; Rodríguez, L. Highlights on gold TADF complexes. Inorganics 2019, 7, 124.

(16) Osawa, M.; Yamayoshi, H.; Hoshino, M.; Tanaka, Y.; Akita, M. Luminescence color alteration induced by trapped solvent molecules in crystals of tetrahedral gold(I) complexes: near-unity luminescence mixed with thermally activated delayed fluorescence and phosphorescence. Dalton Trans., 2019, 48, 9094-9103.

(17) (a) Hall, C. R.; Romanov, A. S.; Bochmann, M.; Meech, S. R. Ultrafast structure and dynamics in the thermally activated delayed fluorescence of a carbene-metal-amide. J. Phys. Chem. Lett. 2018, 19, 5873-5876; (b) Di, D.; Romanov, A.S.; Yang, L.; Richter, J.M.; Rivett, J.P.H.; Jones, S.; Thomas, T.H.; Abdi, Jalebi, M.; Friend, R.H.; Linnolahti, M.; Bochmann, M.; Credgington, D. High-performance light-emitting diodes based on carbene-metal-amides. Science, 2017, 356, 159-163.

(18) Leitl, M. J.; Zink, D. M.; Schinabeck, A.; Baumann, T.; Volz, D.; Yersin, H. Copper(I) complexes for thermally activated delayed fluorescence: from photophysical to device properties. Top Curr Chem. (Z), 2016, 374:25.

(19) (a) Haneline, M. R.; Tsunoda, M.; Gabbai, F. P. $\pi$ Complexation of biphenyl, naphthalene, and triphenylene to trimeric perfluoro-ortho-phenylene mercury. Formation of extended binary stacks with unusual luminescent properties. J. Am. Chem. Soc., 2002, 124, $3737-$ 3742; (b) Omary, M. A.; Rawashdeh-Omary, M. A.; Diyabalanage, H. V. K.; Dias H. V. R. Blue phosphors of dinuclear and mononuclear copper(I) and silver(I) complexes of 3,5-Bis(trifluoromethyl)pyrazolate and the related bis(pyrazolyl)borate. Inorg. Chem., 2003, 42, 8612-8614; (c) Grushin, V. V.; Herron, N.; LeCloux, D. D.; Marshall, W. J.; Petrov, V. A.; Wang, Y. New, efficient electroluminescent materials based on organometallic Ir complexes. Chem. Commun., 2001, 1494-1495; (d) Dias, H. V. R.; Diyabalanage, H. V. K.; Eldabaja, M. G. ; Elbjeirami, O.; Rawashdeh-Omary, M. A.; Omary, M. A. Brightly phosphorescent trinuclear copper(I) complexes of pyrazolates: substituent effects on the supramolecular structure and photophysics. J. Am. Chem. Soc., 2005, 127, 7489-7501.

(20) Dias, H. V. R.; Kim, H.-J.; Lu, H.-L.; Rajeshwar, K.; de Tacconi, N. R.; Derecskei-Kovacs, A.; Marynick, D. S. Investigation of the electronic and geometric effects of trifluoromethyl substituents on tris(pyrazolyl)borate ligands using manganese(I) and copper(I) complexes Organometallics, 1996, 15, 2994-3003.

(21) Dias, H. V. R.; Lu, H.-L.; Kim, H.-J.; Polach, S. A.; Goh, T. K. H. H.; Browning, R. G.; Lovely, C. J. Copper(I) ethylene adducts and aziridination catalysts based on fluorinated tris(pyrazolul)borates $[\mathrm{HB}(3-$ $\left.\left.\left(\mathrm{CF}_{3}\right), 5-(\mathrm{R}) \mathrm{Pz}\right)_{3}\right]^{-} \quad$ (where $\mathrm{R}=\mathrm{CF}_{3}, \mathrm{C}_{6} \mathrm{H}_{5}, \mathrm{H} ; \mathrm{Pz}=$ pyrazolyl) Organometallics, 2002, 21, 1466-1473.

(22) López-de-Luzuriaga, J. M.; Monge, M.; Olmos, M. E.; Rodríguez-Castillo, M.; Soldevilla, I. Versatile coordinative abilities of perhalophenyl-gold(I) fragments to Xantphos: influence on the emissive properties. Journal of Organometallic Chemistry, 2020, 913, 121198.

(23) Osawa, M.; Aino, M. A.; Nagakura, T.; Hoshino, M.; Tanaka, Y.; Akita, M. Near-unity thermally activated delayed fluorescence efficiency in three- and four- coordinate $\mathrm{Au}(\mathrm{I})$ complexes with diphosphine ligands. Dalton Trans., 2018, 47, 8229-8239.

(24) (a) Visbal, R.; López-de-Luzuriaga, J.M.; Laguna, A.; Gimeno, M.C. Three coordinate gold(I) N-heterocyclic carbene complexes: a new class of strongly luminescent derivatives. Dalton Trans., 2014, 43, 328334. (b) Visbal, R.; Ospino, I.; López-de-Luzuriaga, J.M.; Laguna, A.; Gimeno, M.C. N-heterocyclic carbene ligands as modulators of luminescence in three-coordinate gold(I) complexes with spectacular quantum yields. J. Am. Chem. Soc., 2013, 135, 4712-4715.

(25) Crespo, O.; Díez-Gil, C.; Gimeno, M.C.; Jones, P. G.; Laguna, A.; Ospino, I.; Tapias, J., Villacampa, M.D.; Visbal, R. Influence of the group 11 metal on the emissive properties of complexes $\left[\mathrm{M}\left\{\left(\mathrm{PR}_{2}\right)_{2} \mathrm{C}_{2} \mathrm{~B}_{9} \mathrm{H}_{10}\right\} \mathrm{L}\right]$. Dalton Trans., 2013, 43, 8298-8306.

(26) Luong, L. M. C.; Aristov, M. A.; Adams, A. V.; Walters, D. T.; Berry, J. F.; Olmstead, M. M.; Balch, Balch, A. L. Unsymmetrical Coordination of Bipyridine in Three-Coordinate Gold(I) Complexes. Inorg. Chem. 2020, 59, 4109-4117.

(27) See for example: a) Assefa, Z.; Staples, R.J.; Fackler, Jr. J.P. Synthesis, characterizations, luminescence properties, and electronic structures of gold(I) bis(phosphine)-Xantate complexes. Inorg. Chem., 1994, 33, 2790-2798; Khin, C.; b) Hashmi, A.S.K.; Rominger, F. Gold(I) complexes of P,N ligands and their catalytic activity. Eur. J. Inorg. Chem. 2010, 1063-1069; c) Zeltner, S.; Jelonek, S.; Sieler, J.; Olk, R.-M. Synthesis and crystal structures of coinage metal thioether-thiolato complexes. Eur. J. Inorg. Chem. 2001, 1535-1541; d) Khan, M.; Oldham, C.; Tuck, D. G. The direct electrochemical synthesis of triphenylphosphine adducts of group IB monohalides. Can.J. Chem., 1981, 59, 2714-2718; e) Bowmaker, G. A.; Dyason, J.C.; Healy, P.C.; Engelhardt, L.M.; Pakawatchai, C.; White, A. H. Lewis-base adducts of group 11 metal(I) compounds. Part 27. Solidstate phosphorus-31-cross-polarization magic-angle spinning nuclear magnetic resonance, far-infrared, and structural studies on the mononuclear 2:1 adducts of triphenylphosphine with copper(I) and gold(I) halides. J. Chem. Soc. Dalton Trans., 1987, 1089-1097; f) Bowmaker, G.A.; Brown, C.L.; Hart, R.D.; Healy, P.C.; Rickard, C.E.F.; White, A.H. Co-ordination and conformational isomerism in bis(tricyclohexyl-phosphine) gold(I) halides. Chem. Soc., Dalton Trans., 1999, 881-889.

(28) Levason, W.; Reid, G.; Webster, M. 1,2Bis(diphenylphosphino)benzene and two related mono-methiodides, [o$\left.\mathrm{C}_{6} \mathrm{H}_{4}\left(\mathrm{P} R_{2}\right)\left(\mathrm{P} R_{2} \mathrm{Me}\right)\right] \mathrm{I}(R=\mathrm{Ph}$ or $\mathrm{Me})$. Acta Cryst. 2006, C62, o438o440.

(29) Czerwieniec R.; Yersin, H. Diversity of copper(I) complexes showing thermally activated delayed fluorescence: basic photophysical analysis. Inorg Chem., 2015, 54, 4322-4327.

(30) Chiang, C. J.; Kimyonok, A.; Etherington, M. K.; Griffiths, G. C.; Jankus, V.; Turksoy, F.; Monkman, A.P. Ultrahigh efficiency fluorescent single and Bi-layer organic light emitting diodes: the key role of triplet fusion. Adv. Funct. Mater. 2013, 23, 739-746.

(31) Penfold, T. J.; Dias, F.B.; Monkman, A.P. The theory of thermally activated delayed fluorescence for organic light emitting diodes, Chem. Commun. 2018, 54, 3926-3935.

(32) Gadirov, R.M.; Valiev, R.R.; Samsonova, L.G.; Degtyarenko, K.M.; Izmailova, N.V.; Odod, A.V.;.Krasnikova, S.S ; Yakushchenko, I.K.; Kopylova, T.N. Thermally activated delayed fluorescence in dibenzothiophene sulfone derivatives: Theory and experiment. Chem. Phys. Lett. 2019, 717, 53-58.

(33) Valiev, R. R.; Minaev, B. F.; Gadirov, R. M.; Nikonova, E. N.; Solodova, T. A.; Nikonov, S. Yu.; Bushuev, M. B.; Kopylova, T. N. Electroluminescence of Halogen Complexes with Monovalent Copper: OLED Devices and DFT Modeling. Russ. Phys. J. 2016, 58, 1205-1211.

(34) Greiner, J.; Valiev, R. R.; Sundholm, D. Photophysical properties of the triangular $[\mathrm{Au}(\mathrm{HN}=\mathrm{COH})]_{3}$ complex and its dimer. Phys. Chem. Chem. Phys. 2020, 22, 10314-10321.

(35) Valiev, R. R.; Benkyi, I; Konyshev, Y. V.; Fliegl, H.; Sundholm, D. Computational Studies of Aromatic and Photophysical Properties of Expanded Porphyrins. J. Phys. Chem. A, 2018, 122, 4756-4767.

(36) (a) Casado, A. L.; Espinet, P. A novel reversible aryl Exchange involving two organometallics: mechanism of the gold(I)-catalyzed 
isomerization of trans- $\left[\mathrm{PdR}_{2} \mathrm{~L}_{2}\right]$ complexes $\left(\mathrm{R}=\right.$ aryl, $\left.\mathrm{L}=\mathrm{SC}_{4} \mathrm{H}_{8}\right)$ Organometallics, 1998, 17, 3677-3683; (b) Usón, R.; Laguna, A.; Vicente, J.; García, J.; Bergareche, B. Preparation of pentahalophenyl ptolylisocyanide complexes of gold(I) and their reactions with amines, ammonia and alcohols. J. Org. Chem., 1979, 173, 349-355.

(37) Sheldrick, G. M. SHELXL97, Program for Crystal Structure Refinement; University of Go"ttingen: Germany, 1997.

(38) Lee, C.; Yang, W.; Parr, R. G. Development of the Colle-Salvetti correlation-energy formula into a functional of the electron density. Phys. Rev. B: Condens. Matter Mater. Phys., 1988, 37, 785-789

(39) Rassolov, V. A.; Ratner, M. A.; Pople, J. A.; Redfern, P. C.; Curtiss, L. A. $6-31 \mathrm{G}^{*}$ basis set for third-row atoms. J. Comput. Chem. 2001, 22, 976-984.

(40) Andrae, D.; Haeussermann, U.; Dolg, M.; Stoll, H.; Preuss, H. Energy-adjusted $a b$ initio pseudopotentials for the second and third row transition elements. Theor. Chim. Acta 1990, 77, 123-141.

(41) Schmidt, M. W.; Baldridge, K. K.; Boatz, J. A.; Elbert, S. T.; Gordon, M. S.; Jensen, J. H.; Koseki, S.; Matsunaga, N.; Nguyen, K. A.; Su, S.; Windus, T. L.; Dupuis, M.; Montgomery, J. A. General atomic and molecular electronic structure system. J. Comput. Chem., 1993, 14, 13471363.

(42) Fedorov, D. G.; Koseki, S.; Schmidt, M. W.; Gordon, M. S. Spin-orbit coupling in molecules: Chemistry beyond the adiabatic approximation. Int. Rev. Phys. Chem. 2003, 22, 551-592.

(43) Granovsky, A. A. Extended multi-configuration quasidegenerate perturbation theory: The new approach to multi-state multireference perturbation theory. J. Chem. Phys. 2011, 134, 214113.

(44) Granovsky, A. A. Firefly version 8, www http://classic.chem.msu.su/gran/firefly/index.html 
For Table of Contents Only

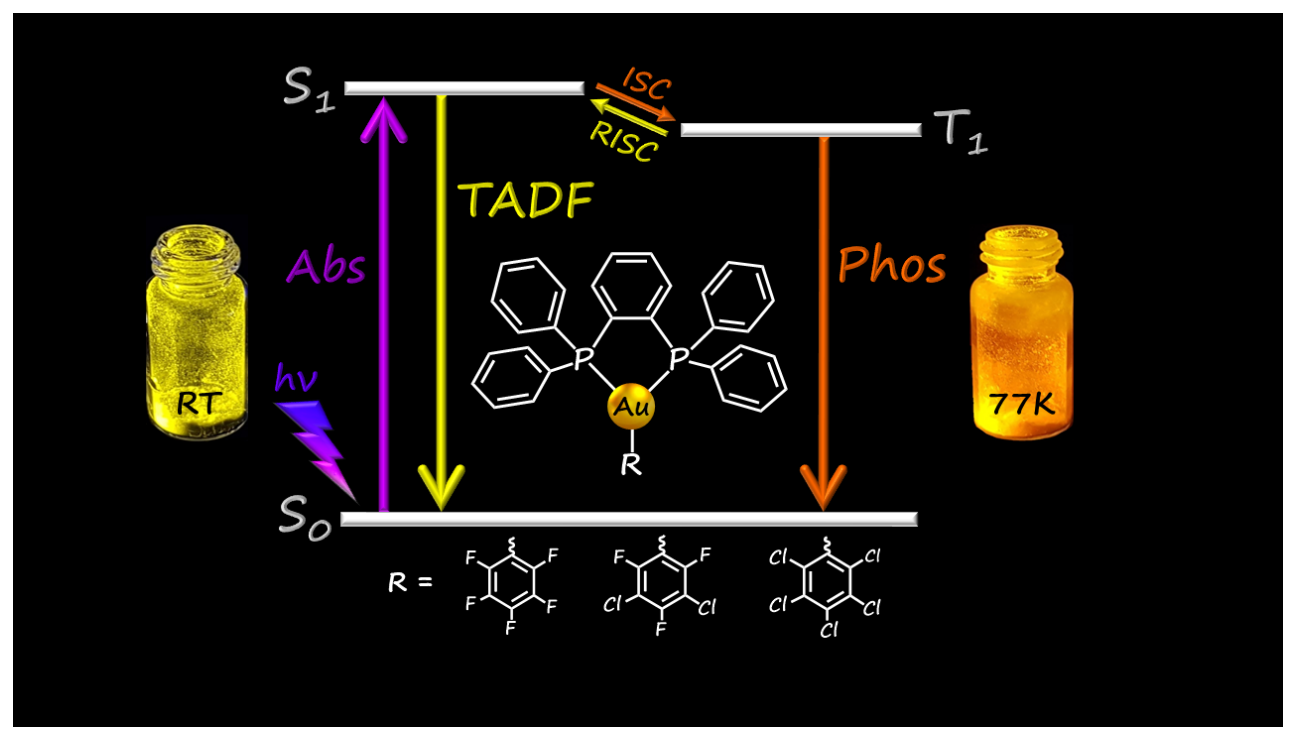

Perhalophenyl three-coordinate $\mathrm{Au}(\mathrm{I})$ complexes $[\mathrm{AuR}(\mathrm{dppBz})]$ displaying distorted trigona planar coordination environments show interesting thermally activated delayed fluorescence (TADF) emitting properties in solid state at RT. 